\title{
Forma de Propriedade, Capitalismo e Ética do Trabalho no Brasil: para uma crítica de Max Weber (1)
}

\author{
Alfredo Attié Junior \\ Professor do Departamento de Filosofia, da Faculdade de Direito da \\ Universidade de São Paulo \\ “... aquilo de que se trata e a ciência e na ciência o conteú- \\ do encontra-se essencialmente ligado à forma." (HEGEL, \\ Princípios da Filosofia do Direito) \\ "O espírito das leis e a propriedade" (LINGUET, citado \\ por MARX, $O$ Capital.
}

\begin{abstract}
RESUMO: O artigo propõe uma recuperação do tema da propriedade no direito, discutindo a concepção das relações de trabalho no Brasil, através das fontes históricas, iniciando, assim, uma crítica à concepção weberiana da relação entre religião e capitalismo.
\end{abstract}

RESUMÉ: L'article propose une récuperation de la question de la proprieté en droit, en discutant la concéption des rapports de travail au Brésil, à travers des sources historiques, et dessine une critique à la concéption weberienne des rapports entre religion et capitalisme.

I - No interior do pensamento marxiano, em sua transparência e não temor, na fidelidade ao método dialético, de deixar claras contradiçōes e limites, pode-se vislumbrar a convicção da ocorrência de uma ruptura lógica e histórica no percurso do homem. Com efeito, o advento do capitalismo marca uma nova fase da existência humana, a tal ponto fundamental que todo o ocorrido anteriormente, malgrado correspondendo a um período de tempo muito maior, pode ser entendido como uma unidade, contraposta a esta nova estrutura.

O capitalismo significa uma formação social que rompe com uma unidade entre existência e consciência, instaurando o mundo da alienação e da ideologia. É o momento de separação do homem das condições de sua existência meio e materiais de trabalho - quando assim expropriado passa a ser concebido

(1) Trabalho respeitosamente dedicado à Professora Doutora Izabel Andrade Marson. São Paulo, novembro/dezembro de 1986. Na 10ª Conferência Interamericana de Advogados, Buenos Aires-Argentina, 1987. 
como indivíduo isolado da comunidade em que vive, trabalhador livre, não mais proprietário senão de sua força de trabalho, alienada na produção e trocada no mercado por dinheiro com o objetivo de a este reproduzir, consumida como seu valor de uso. Se, antes, o homem se apresentava como senhor de sua existência, porquanto proprietário, por intermédio da comunidade a que pertencia, da terra e dos instrumentos de sua exploração, vale dizer, dono de sua vida, em todos os seus aspectos, agora esta unidade se vê quebrada: pensamento e existência não mais se correspondem, ser e consciência de ser separam-se. A ordem do capital, instauradora da alienação humana, em seu mais alto grau, cria condiçōes para, num mundo dividido entre indivíduos proprietários e indivíduos privados da propriedade das condiçōes objetivas de existência, ergue-se uma barreira para a visão e pensamento do real, a qual busca eternizar aquela ordem, em verdade historicamente explicável.

Não nos preocupa, aqui, descrever aquilo que podemos chamar de modo de ser conservador, pautado pela necessidade de esconder aquilo que parece ser o vício original da estrutura capitalista - a expropriação como reverso da acumulação - apenas sublinhemos que a sua superação somente pode ser alcançada a partir de um esforço de realização de mais este compendiumm ${ }^{(2)}$.

O que interessa é notar como, paulatinamente na fala marxiana, vai-se delineando o caráter fundamental da análise das formas de propriedade.

Assim, é a produção que interessa, não qualquer outra atividade. Produção pelos homens de sua existência. Apropriação da natureza e sua transformação constante. É sobre a propriedade que se fundamenta o modo de ser social. Como os homens se apropriam das condições existenciais, assim eles são. Modo de produzir é modo de ser. Forma de propriedade significa forma de ser. A propriedade é o núcleo, determina o estatuto da pessoa e está intimamente ligada às comunidades naturais. A produção exerce uma tirania! Todas as outras atividades não são senão reprodução; a ela se submetem; têm sua forma determinada pelo modo de produzir.

Tal domínio da propriedade perpassa, sem fragmentação, a totalidade do real. Descarte, a mudança das formas de propriedade anteriores para o capitalismo é acompanhada do surgimento da concepção da propriedade como poder, como faculdade, engendrada como direito subjetivo. Afinal, é ao indivíduo e a seus direitos que se atém a sociedade moderna. $\mathrm{E}$ o indivíduo não é outro senão o ser isolado e, assim, desigual.

(2) V. A identidade do outro: ensaio sobre as formas de propriedade no Brasil, São Paulo/Viena, outubro/1986. 
II - Ora, esta mudança, que parece ser a fundamental, vai ocorrer no interior do pensamento católico, na primeira metade do século XIV. Encontrará seu pleno desenvolvimento, já a partir do século XVI, na doutrina (Suarez e de Vitória, por exemplo) e na prática da Companhia de Jesus, ordem de certo modo responsável pela inserção da Igreja Católica no mundo moderno. Se coube aos franciscanos, na figura do nominalista Ockham, dar os primeiros passos na atualização do direito às necessidades de um processo de crescente individuação e liberação do homem das ligaçōes que tinha com a terra, e da propriedade de seu modo de existir, caberá aos jesuítas a plena expansão desta doutrina, no amplo campo de ação que lhes foi reservado, resultado de suas missōes, espalhadas por quase todo o mundo colonial moderno.

Ad majorem, Dei gloriam, na prática e em sua descrição, os missionários demonstrarão a plena eficácia de sua ética de trabalho, preenchida, cabalmente, pelo espírito do capitalismo.

Com isto queremos dizer não apenas que os jesuítas desempenharam um papel de extrema relevância naquele processo que se convencionou chamar de aculturação ou cristianização dos povos, em verdade expansão da civilização ocidental, então impregnada por nova alma, cuja dinâmica não mais admitiria a exterioridade ou a alteridade - onde as encontrasse ou destruí-las-ia ou faria transformá-las à sua imagem (imagem da dominação política, da desigualdade social, da exploração econômica). Recolhamos algumas passagens do relato do Pe. Sepp (3): "não quero falar aqui de como minha rica roupeta de Cádiz estava toda rota... porém e agora, ele (Deus) tudo me substituiu e restituiu mil vezes... verdadeiramente como ele me cumulou"... "Quando via a terra americana, nāo pude conter-me de chorar de alegria... A terra, 'nota bene', é tão fértil, que por toda parte encontrarás uns doze a quinze mil bois e vacas... são livres e não fazem parte de nenhum rebanho... nosso colégio, recentemente, mandou reunir $\mathbf{2 0 . 0 0 0}$ cabeças de gado e os vendeu por 12.000 Talers. Portanto, a cabeça sai mal por um Gulden. Não seria um alto negócio para os mercadores de gado e corretores da Europa!" Por detrás da caridade católica do padre mal se esconde um dircurso de dominação, com vistas à acumulação de bens. "... Há aqui índios e negros (ambos bons católicos) e espanhóis... De resto são estes paraguaios cristãos muito bons e piedosos, a ninguém submissos a não ser aos nossos Padres, amando-os assim como o filho ama ao pai. Somos nós que os vestimos, instruímos e educamos. São muito aplicados e imitam tudo que vêem". Não há separação entre aquelas preocupaçōes e as especificamente religiosas (é óbvio que especifidade não existe, as ações religiosas são a forma de que se revestem as

(3) O relato é de 1691. 
práticas econômicas e políticas): “... benévolo leitor, mal adivinhas onde realmente estavam! Estavam, ah, onde, em circunstâncias idênticas, deveriam estar as mulheres européias, estavam todas juntas reunidas no Senhor... Quem é que não choraria de puro consolo, como deste modo as pobres coitadas adoram ao seu Deus, a quem, faz pouco ainda, não conheciam e nem veneravam"'... "Vamos considerar um pouco a situação de nossas reduçōes, assim chamadas porque todos esses índios são por nós 'reduciret' (conduzidos) à fé cristā... Ao todo há 26 reduçōes. Cada uma é administrada por dois Padres... Consta uma redução destas, três, quatro, cinco, seis mil e mais almas. Todos eles... confessam ao menos quatro vezes por ano... Todas estas confissões o Padre precisa ouvir e absolver, distribuir a comunhão... precisa ser o sacristão. Tudo isto se refere ao espiritual... passemos agora para a economia e administração dos bens terrenos, que não se referem a uma só pessoa, mas à dos índios... O Padre precisa ser tudo a todos... tudo quanto pode haver ainda de funçōes numa república bem organizada, numa comunidade, cidade ou num 'Collegium Societas', ou num convento da Santa Ordem". No episódio do sal, a inferioridade intelectual, sinônimo da diferença, é expressamente declarada: "6 'Nāo notas, meu filho' - o apelativo sempre é 'fillho', assim como eles nos chamam de 'pai'... que não posso comer esta sopa por estar muito salgada"... Depois: “"... estes índios são tão pueris, tão grandemente simplórios e de juízo tão curto, que os primeiros Padres, que converteram estes povos, duvidaram realmente se eram capazes de receber os Santos Sacramentos"... A América é rica, os índios preguiçosos, é preciso discipliná-los para produzirem "... mas nós não conseguimos fazer com que os índios, em sua pura preguiça, semeiem mais de uma ou duas rocinhas de 18 passos de grão turco". O discurso caridoso afinal, desfaz-se: "E mesmo isto só o conseguimos com tundas. Assim domingo passado tornou-se absolutamente necessário passar uma sova em alguns índios que nāo haviam assentado a terra e nem haviam procurado encontrar um arado... E não davam conta nem deste pedacinho de roça, deste punhado de terra, se o Padre não apertava o agricultor preguiçoso com sovas e inspeçōes incessantes".

A produção precisa ser calculada e o produtor disciplinado. Por seu trabalho recebe aquilo que o Padre paga, na maneira como estabelece. É preguiçoso, imprevidente e ingênuo, porém, muita vez, é a sua própria tecnologia de exploração da terra que é empregada, desenvolvida ao máximo, para a produção ao mercado (o cálculo de valores de troca não abandona a mente do bom Padre Sepp).

Porém, dizíamos, não é apenas nesta tarefa de destruição do modo de ser da população não-européia que se empenham os jesuítas. Foi também na disciplina da produção e na ética de trabalho que forneceram importante contribui- 
ção. Isto fica patente na crônica de Sepp, e resta inafastável nos manuais de Benci $^{(4)}$ e Antonil ${ }^{(5)}$.

III - O que diz respeito à demonstração do cabedal necessário ao senhor de engenho, à narração de seu governo, da especialização das tarefas, das atividades desenvolvidas nas fábricas, na cuidadosa contabilidade, etc., do trabalho de Antonil, fica clara sua finalidade de acumulação e seu caráter de planejamento consciente e eficiente de uma atividade. $O$ que nos interessa mais de perto, entretanto, é a visão do escravo apresentada pelos dois missionários (da descrição de Antonil, diga-se de passagem, percebe-se não ser ele senão um dos múltiplos sujeitos do processo de produção). A estes economistas jamais espantaria, se o tivessem testemunhado, o fato de o projeto constitucional de 1823 declarar: "A Constituiçäo reconhece os contratos entre os senhores e escravos; o governo vigiará sobre sua manutenção". Estar-se-ía tratando de sujeitos de direito? Não eram, pois, os escravos meros instrumentos ou coisas?

Os estudos de Benci e Antonil demonstram que o escravo não se mostrava como coisa, mas como pessoa, sujeito de direitos e deveres, titular de prestaçōes e contraprestações. Trata-se de um trabalhador decaído, não de um ser inferior por natureza. São criaturas racionais, constam de corpo e alma - o contraste com a descrição aristotélica é gritante! Devem ser alimentados e disciplinados, pela correção (a punição, aliás, só se admite se justa e precedida de devido processo, onde o escravo é ouvido) e pelo trabalho.

Neste sentido, algumas questōes chamam a atenção em Benci: 'De todos os bens naturais o único de que goza o escravo é a saúde: $O$ bem da riqueza, não o alcança, porque nada tem de seu, pois pertence ao senhor tudo o que lucra" (q. 47)... "A desculpa comum e vulgar dos senhores e senhoras do Brasil nesta matéria, é dizerem que suas posses não chegam a poder vestir tanto número de escravos e escravas. Boa razão era esta se eu obrigasse a dar-lhes vestido e galas de grande preço. Mas nem eu, nem Deus obriga a tanto, senāo só a cobrir de tal sorte os escravos e principalmente as escravas, que não andem indecentemente vestidos" (q. 41)... "por isto com grande propriedade se chama a este sustento presa 'deditque praedam'. Notai agora a grande providência desta Mulher, a qual entendendo que os servos e as servas não podiam trabalhar sem comer, e não deviam comer sem trabalhar, no mesmo tempo repartia entre eles a raçáo e as tarefas... para que houvesse a mútua correspondência entre o sustento e o trabalho, de sorte que tendo os servos o sustento pudessem trabalhar, e

(4) Datado de 1700.

(5) Datado de 1711. 
tendo o trabalho pudessem merecer o sustento" (q. 197)... "Enquanto o senhor traz o servo ocupado, não cuida esse em outra coisa (diz o Espírito Santo) mais que no descanso. Porém se lhe larga a mão, logo aspira à liberdade e busca traças para se livrar da sujeição" (q. 200).

O mesmo em Antonil: "No Brasil costumam dizer que para o escravo são necessários três PPP, a saber, pau, pão e pano... Costumam alguns senhores dar aos escravos um dia em cada semana, para plantarem para si, mandando algumas vezes com eles o feitor, para que não se descuidem... E se, em cima disto, o castigo for freqüente e excessivo, ou se irão embora fugindo para o mato, ou se matarão por si, como costumam"'... Se "os escravos são as mãos e os pés do senhor de engenho", "os braços de que se vale... para o bom governo da gente e da fazenda, são os feitores" (Livro I).

Nos textos transcritos se observa que, malgrado chamando os trabalhadores de escravos, nesta condição não se apresentam aos jesuítas. Pergunto se não seria melhor denominá-los trabalhadores escravizados, pois não há sempre que se precaver para não terem consciência da liberdade de que são dotados? Que liberdade seria esta? Ela os faz pessoas e, sabemos, desde a ruptura e o momento novo que o capitalismo instaura (anteriormente também, mas de forma diversa), só quem possui algo pode ser, verdadeiramente, livre. $\mathrm{E}$ isto vale, também, para os privados de propriedade: os trabalhadores livres. São livres porque isolados (libertos) dos meios de existência, mas também porque proprietários de sua força de trabalho. Se esta condição, entendida estritamente, é pressuposto do capitalismo, como entender a posição dos escravizados? Não têm a propriedade de sua força de trabalho (de sua vida), obviamente, pois esta pertence aos outros. No entanto, permanecem com sua posse (direta). $O$ ato pelo qual perdem a propriedade (e a posse indireta) é um ato jurídico, pode-se afirmar até que seja um contrato. "Mas é um ato de força!", exclamarão os idealistas... entretanto, respondemos, qual contrato não o é?

Daí os escravizados são tidos como sujeitos e não como coisas. Têm capacidade, mesmo que limitada ao exercício de suas obrigaçōes e ao recebimento de seu jornal, contraprestação esta que nunca corresponde ao que se produziu, mas é sinal de apropriação, pelo senhor, do valor a mais criado no trabalho.

Tratar-se-ía de escravos, de escravos modernos, mas apenas por não ter ocorrido a ninguém chamá-los diferentemente. Porque, em verdade, são trabalhadores livres que jamais como tais conceber-se-ão... são escravizados, perdem a vida porém permanecem com seu exercício, contratam, mas sem o saber, permitindo que se crie um mercado de sua força de trabalho enriquecedor de seus sucessivos proprietários.

A conclusāo, então, não é a da compatibilidade entre produção capitalista 
e instituição do trabalho escravo, como quer Maria Sylvia Carvalho Franco. Mas a de que o trabalhador não é escravo, e sim livre (mais propriamente escravizado)! A exploração de seu trabalho é tão eficaz, tão grande é sua alienação, tão eficiente é a ideologia que ele não se verá assim. No discurso, porém, dos teóricos da dominação, como vimos, é possível flagrar tal dissimulação... a descoberta da liberdade era um fato sempre em via de ocorrer.

Tudo isto mais se esclarece ao comparar tal discurso àquele produzido por Aristóteles a propósito do escravismo antigo. Ali há a plena e satisfatória distinção entre escravo e livre, sobretudo porque dada, em geral, pela natureza: "é um escravo por natureza quem é suscetível de pertencer a outrém (e por isto é de outrém), e participa da razão somente até o ponto de apreender esta participação, mas não a usa além deste ponto... Na verdade, a utilidade do escravo pouco difere da dos animais... O escravo é parte da propriedade". É coisa, é o instrumento que fala (instrumentum vocale).

Heidegger afirmou, em Ser e Tempo, que "a aparência de alguma coisa não significa que ela se mostra, mas que se anuncia através de algo que não se mostra". Se correto, será razão para divergirmos de M. Sylvia Carvalho Franco. A instituição que se apresenta não é a da escravidão. Se assim fora, acabar-se-ía por dar razão aos seus adversários, os quais se desejam mais ortodoxos. Pois Marx não afirmou que os trabalhadores livres o são "no duplo sentido, porque não pertencem diretamente aos meios de produção, como os escravos, os servos, etc., nem os meios de produção lhes pertencem, como por exemplo, o camponês economicamente autônomo etc., estando pelo contrário, soltos e desprovidos deles" (O Capital); e que ao ser o próprio homem "capturado como um acessório orgânico da terra e junto com ele, sua captura dá-se na qualidade de uma das condiçōes de produção, e esta é a origem da escravidão e da servidão, que logo degradaram e modificaram as formas originais de todas as comunidades" (Grundrisse)? De nada adiantam a ortodoxia, de um lado (porquanto cega e atemporal), e a reconstrução lógica (malgrado possivelmente correta), por outro. E preciso superar, eis que o importante não é a adequação a um modelo, mas a sua prova, perante o tribunal da praxis, seu abandono diante do que a realidade dos conflitos transforma.

IV - Pelo que foi dito, bem clara já se delinea a contestação aos trabalhos de Weber, os quais, parece, dividem a preferência dos estudiosos com os de Marx. No que se refere, aliás, ao estudo das formas de produção no Brasil, parece que a opção (mais ou menos consciente ou confusa) têm sido pelo ramo weberiano (referimo-nos, sem exagero, a Sérgio Buarque de Hollanda, Gilberto Freyre, Celso Furtado, Fernando Henrique Cardoso, Raymundo Faoro, e até Ciro Flammarion Cardoso, Caio Prado Junior, Fernando Novais e Antonio Barros de Castro). Isto fica patente sobretudo, quando não assumem a "categoria" da totalidade ("o todo é a verdade", afirmava Hegel na Fenomenologia do Espírito) e a determinação do modo de existência pela produção e ao recusa- 
rem a característica da universalidade e não-exterioridade, da tendência à corrosão das formaçōes incompatíveis com sua dinâmica própria - a da mercadoria - (ou, no mínimo, permitindo que subsistam nominalmente, porquanto outra alma passe a lhes dar vida... ou a tirá-la) do capitalismo.

Weber, no afã de contestar as conclusōes marxianas, que toma de forma apressada e superficial, postura até certo ponto explicável, dados os desenvolvimentos do marxismo a que assistiu e ao desconhecimento de parte fundamental da produção de Marx, o que, entretanto, nada justifica, face ao idealismo weberiano e ao caráter conservador e, ousaríamos dizer, às vezes acrítico de sua obra - acaba buscando as determinações do capitalismo em lugar errado, chegando mesmo, dadas as características de seu método, a nada dizer sobre as suas origens: fornece um rol de elementos do sistema, rompendo com sua historicidade, visualiza-os em várias épocas diversas, somente lhes fornecendo uma unidade a partir da existência de um aspecto ideal - o seu espírito. Este espírito somente se desenvolve no momento em que a ética protestante supera a ética dual originária do judaísmo, destarte golpeando mortalmente a visão mágica do mundo. Como tardio prócere do racionalismo, fornece-lhe um lugar de extrema relevância no capitalismo; como defensor do idealismo, muito embora em seu aspecto mais estático, trabalha com mentalidades, os sujeitos de sua história não são homens concretos, mas tipos ideais, oblitera os conflitos. Sua análise parece extremamente lógica e insípida. Malgrado insista na tecla de neutralidade axiológica, sua análise do capitalismo encontra-se marcada por um preconceito básico: o desconhecimento da colonização portuguesa e espanhola não o faz relativizar as conclusões, e sim, ao contrário, generalizar suas análises do mundo europeu e colonial britânico - sua perspectiva, muito embora particularizante ao extremo, quer-se universal.

Weber definiu o capitalismo como um sistema onde a satisfação das necessidades de um grupo humano se realiza com caráter lucrativo e por meio de empresas. Uma exploração racionalmente capitalista seria uma exploração com conta de capital, isto é, uma empresa lucrativa que controla sua rentabilidade na ordem administrativa por meio da contabilidade moderna. Não haveria, na concepção weberiana, qualquer óbice para convivência de diversas, digamos, atitudes de produção (uma capitalista, outra artesanal ou senhorial), muito menos uma complementariedade entre separadas (por ele) esferas do social ("enquanto nossas necessidades diárias se encontram cobertas por métodos capitalistas, as políticas, entretanto, o são por procedimentos litúrgicos"'). $\mathrm{O}$ capitalismo teria surgido apenas na segunda metade do século XIX, e sua condição prévia é a contabilidade racional do capital, como norma para todas as grandes empresas lucrativas que se ocupam das necessidades cotidianas.

O capitalismo, pois, é algo de ideal, é um dever-ser... É um sistema que não surge com o capital, mas com seu tratamento racional... Acontece na mente 
dos homens, opera com o progresso (intelectual) humano, e menos com as transformações que os conflitos intersubjetivos (ou sociais) fazem ocorrer... haveria real conflito para Weber? O real encontra-se fragmentado, não há continuidade entre o tecido social e cada uma de suas partes pode ter uma determinação diversa. Sintamos os ecos disto nos discursos sobre (ou para) a modernização... nas visōes de exterioridade metrópole-colônia, atraso-avanço, razãoacaso, arcaísmo-modernidade, dependência-autonomia, etc.

Prossigamos: para Weber, aquelas empresas têm, como condições prévias, a apropriação de todos os bens materiais de produção como propriedades de livre disposição por parte das empresas lucrativas autônomas; a liberdade de mercado - superação de toda irracional limitação ao comércio; técnica racional - contabilizável ao máximo, ou seja, planejamento controlável; direito racional - quer dizer, calculável, as decisões devem ser previsíveis; trabalho livre: pessoas obrigadas a vender livremente sua atividade num mercado; comercialização da economia - especulação.

Se fosse proceder a uma crítica superficial do sociólogo alemão (se é que do sociólogo alemão se trata, posto ter-se tornado costume, sobretudo no Brasil, referir-se ao Weber americano, aquele que a sociologia norte-americana reconstruiu), lembraria apenas que é também no interior da Igreja, no final do século $\mathrm{XV}$, que nasce a contabilidade moderna, o sistema da doppia scrittura. $\mathrm{E}$, se ocorre neste instante, é para atender a mudanças que são concomitantes. Não se trata, é claro, apenas disto.

Completemos o quadro: numa passagem extremamente simplista de crítica ao "mais ingênuo materialismo histórico", afirma que o espírito do capitalismo antecede o "desenvolvimento capitalista". Ora, pergunta, na terra de Franklin não teria antecedido de dois séculos e meio o surgimento do capitalismo? A passagem, sem dúvida, é extremamente infeliz.

O espírito do capitalismo seria a atitude que busca o lucro, mas racional e sistematicamente, porquanto a auri sacra fames é algo inerente ao homem e, se satisfeita de forma desenfreada, não leva a qualquer desenvolvimento do capitalismo. Se tudo é ordem, ou melhor, se tudo deve ser ordem, prossegue Weber em suas relações de causa e efeito, o espírito do capitalismo somente poderia ter nascido no interior de uma ética que superasse a dicotomia "moral de grupo" - "moral com referência a estranhos", num golpe final à concepção mágica do mundo, superando os entraves que a Igreja Medieval havia plantado (supressão dos consilia evangelica, das personalidades rigidamente religiosas, etc.). Para ele, afinal, "ganhar dinheiro dentro da ordem econômica moderna é, enquanto for feito legalmente, o resultado e a expressão da virtude e da eficiência em uma vocaçāo" (que se transmuda em "profissão"). “Tais virtude e eficiência são a razão e o fim do espírito do capitalismo". 
Weber abandonou, de fato, a Igreja na Idade Média. Não percebeu o papel que esta desempenhou - sobretudo pelas mãos dos jesuítas - na expansão e dominação do mundo moderno. Por isto não notou como a ética católica, junto com o advento do capitalismo, transforma-se numa ética da produção para acumulação, de produção para o lucro. Ganhar dinheiro legalmente... sim, mas enquanto o espírito da lei é "(de consacrer) la proprieté", e a perda da propriedade é o vício original que instaura, para sempre, o conflito no capitalismo. Acumulam alguns, enquanto expropriam outros. Não teria sido a virtude católica mais eficiente? Mas, que virtude católica, que ética protestante, que espírito do capitalismo? Uma nova ordem havia sido fundada e ela preencheu todas as formaçōes anteriores com sua alma ${ }^{(6)}$, a dinâmica da mercadoria, a alma do capital.

(6) Se Weber preferia o termo "espírito" (Geist), o que não deixa de ser sintomático, havemos de fixar "alma", que, mesmo na tradição religiosa, parece ter um sentido muito mais concreto, correspondendo mesmo a uma forma de ser. 